\title{
The molecular characterization of Mycoplasma agalactiae isolates from Iranian goats when compared with other Iranian isolates and vaccinal strains
}

\author{
Babak Kheirkhah $^{1^{*}}$, Seyed Ali Pourbakhsh ${ }^{2}$, Abbas Ashtari $^{2}$, Mohammad Ali Bayatzadeh $^{3}$, \\ Kumarss amini ${ }^{4}$ and Alireza Abtin ${ }^{3}$ \\ ${ }^{1}$ Department of Microbiology Science, Baft Branch, Islamic Azad University, Baft, Iran. \\ ${ }^{2}$ Reference Mycoplasma Laboratory, Razi Vaccine and Serum Research Institute, Karaj, Iran. \\ ${ }^{3}$ Pasargad Research Group, Tehran, Iran \\ ${ }^{4}$ Department of Microbiology Science, Saveh Branch, Islamic Azad University, Saveh, Iran.
}

Accepted 2 January, 2013

\begin{abstract}
Mycoplasma agalactiae is the etiological agent of contagious agalactia, which is the first isolated mycoplasma from sheep and goats. The bacteria have been detected using polymerase chain reaction (PCR) method in Iranian goats, but there has been no investigation of the molecular characterization of contagious agalactia agents in goats in Iran. Several studies have also characterized M. agalactiae strains. The aim of this study was to analyze the DNA sequence of M. agalactiae isolates from Iranian goats, and compare it with the other Iranian isolates and vaccinal strains obtained from GenBank. Therefore, PCR with a mycoplasmal cytoplasmic membrane protein $80 \mathrm{KDa}$ (P80) gene was applied to Iranian isolates and the PCR product was purified and sequenced. After the computer alignment of these gene sequences was done, the next process was comparing the result with the specific species of $M$. agalactiae deposited in GenBank. However, a sequence identity matrix is represented (Bio Edit, Clustal W) and a phylogenetic tree is built by the neighbor-joining method. 1000 bootstrap simulations were given at the tree's branching points and represent these points' phylogenetic relationships. Sequence analysis of different $\boldsymbol{M}$. agalactiae showed significant variability among the field isolates. In comparison with vaccine strains, which are used in Iranian goat herds, characterized isolates under this study has a poor homology.
\end{abstract}

Key words: Mycoplasma agalactiae, contagious agalactia, molecular characterization, goat, Iran.

\section{INTRODUCTION}

Mycoplasma infections of small ruminants are known to exist mainly in the Mediterranean region, but are also reported in many other areas of the world (Zendulkova et al., 2007) such as Iran. Among the more significant Iranian goat diseases, mycoplasmal infections result in substantial losses. Mycoplasma agalactiae is a dominant mycoplasmal cause of natural disease in both goats and

*Corresponding author. E-mail: babakkheirkhah@iaubaft.ac.ir Tel: +983474220025 or +989133454787. Fax: +983474220023. sheep. It is endemic in Iran and characterized by agalactia, mastitis, arthritis, keratoconjunctivitis, and sometimes abortion and pneumonia (Hasanitabatabayi et al., 2005). Recently, many investigations have been focusing on the detection of mycoplasmal infection agents, via polymerase chain reaction (PCR) and molecular studies of discovered bacteria (van Kuppeveld et al., 1992; Moradi Bidhendi et al., 2011). Molecular studies of the different mycoplasma species helps in understanding the distribution and epidemiology of the disease status.

PCR with mycoplasmal 16S rRNA has been applied in detecting a variety of mycoplasma species (Zendulkova 
Table 1. Primers and nucleotide sequences used for identification of $M$. agalactiae by PCR.

\begin{tabular}{cclcl}
\hline Primer & Target gene & Sequence & Length (bp) & Reference \\
\hline FS1 & P80 & F: 5'-AAAGGTGCTTGAGAAATGGC-3' & 375 & Tola et al., 1997 \\
FS2 & P80 & R: 5'-GTTGCAGAAGAAAGTCCAATCA-3' & 375 & Tola et al., 1997 \\
\hline
\end{tabular}

et al., 2007; Kojima et al., 1997; De La Fe et al., 2009). Computer alignment studies of these rRNA sequences have revealed the existence of regions with highly conserved sequences and areas which display sequence variability at the genus and species levels, allowing the selection of genus- and specie-specific primers for the PCR (van Kuppeveld et al., 1992). The rRNA was naturally present in high-copy numbers (up to 10,000 molecules per cell) (Waters and McCutchan, 1990). On the other hand, some research findings indicate that assays based on the lipoprotein gene are more specific and sensitive in the detection of $M$. agalactiae in actual natural samples and thus can be a promising alternative tool for the diagnosis and epidemiological studies of $M$. agalactiae (Oravcová et al., 2008).

Again, the detection of $M$. agalactiae by PCR based on the cytoplasmic membrane protein $80 \mathrm{KDa}$ (P80) gene from Iranian goats was reported. However, no investigations exist on the molecular characterization of contagious agalactia agents in goats in Iran. Mahdavi et al. (2009) amplified, cloned and sequenced the P40 gene of vaccinal $M$. agalactiae strains in Iran. This gene sequence was compared with other strains in the gene bank with the BLAST program and some researches were reported regarding the detection and molecular characterization of the species causing other mycoplasmal diseases. The aim of this study was to analyze P80 gene sequence of $M$. agalactiae isolates from Iranian goats, and compare them with other Iranian strains obtained from GenBank.

\section{MATERIALS AND METHODS}

\section{Organisms}

Nineteen strains of $M$. agalactiae were isolated for this study. These strains were provided by Kheirkhah et al. (2011). Razi Vaccine and Serum Research Institute, Karaj, Iran, in a previous study. All strains were grown in humid air with $5 \% \mathrm{CO}^{2}$ at $37^{\circ} \mathrm{C}$ for 24 to $48 \mathrm{~h}$ in liquid mycoplasma medium $(\mathrm{pH} 7.6$ to 8$)$ which contained $10 \mathrm{ml}$ of basal medium [2.1\% (W/V) PPLO broth (Biolife), $0.01 \%(\mathrm{~W} / \mathrm{V})$ glucose and $0.002 \%(\mathrm{~W} / \mathrm{V})$ phenol red] supplemented with additive [20 ml of equine serum, $1 \mathrm{ml}$ of $25 \%$ (W/V) b-nicotinamid-adenine dinucleotide, $0.5 \mathrm{ml}$ of $4 \%(\mathrm{~W} / \mathrm{V})$ thallous acetate and $0.5 \mathrm{ml}$ of 50000 units of penicillin G potassium]. According to European Pharmacopoeia (2005), the negative control was PPLO broth media and the standard positive control was M. agalactiae (NCTC 10123).

\section{DNA extraction}

DNA was extracted from enriched samples according to the follow- ing procedure: A $500 \mu \mathrm{l}$ sample was placed in a $1 \times 5 \mu$ l Eppendorf tube and micro centrifuged at $13000 \mathrm{rpm}$ for $15 \mathrm{~min}$. $100 \mu \mathrm{l}$ of lyses buffer was added to $100 \mu \mathrm{l}$ of precipitate and the tube was placed in a $56^{\circ} \mathrm{C}$ bath for $4 \mathrm{~h}$. Then, $200 \mu \mathrm{l}$ saturated phenol was added and the tube was centrifuged at $13000 \mathrm{rpm}$ for $20 \mathrm{~min}$. The upper phase was transferred to another tube with equal volume of mixed phenol/cholorophorm (1:1). After centrifuging at $13000 \mathrm{rpm}$ for 20 min the aqueous phase was transferred to another tube to which an equal volume of pure cholorophorm was added. This was centrifuged at $13000 \mathrm{rpm}$ for $5 \mathrm{~min}$. The upper phase was transferred to a new tube and mixed with a 1/10 volume of acetate sodium (3 M), which was then precipitated in a $-20^{\circ} \mathrm{C}$ refrigerator with a 2 -fold volume of cool and pure ethanol (20 min), after which the tube was centrifuged at $13000 \mathrm{rpm}$ for $15 \mathrm{~min}$. $200 \mu \mathrm{l}$ of $70 \%$ ethanol was added and the tube was centrifuged at $13000 \mathrm{rpm}$ for 5 min. The DNA was dried and re-suspended in DDW at $4^{\circ} \mathrm{C}$, to be used for PCR (Kojima et al., 1997).

\section{PCR}

For M. agalactiae-specific amplification, the primer set FS1 and FS2 was used. The primer sequences and their corresponding genes are shown in Table 1.

DNA amplification was carried out in a total volume of $35.25 \mu \mathrm{l}$ containing $17.5 \mu \mathrm{l}$ of DNA, $0.1 \mu \mathrm{l}$ of each primer, $0.5 \mu \mathrm{l}$ of dNTP mix (10 mM) \{Roche\}, $4 \mu \mathrm{l} \mathrm{MgCl} 2$ (25 mM) \{Roche\}, $2.5 \mu \mathrm{l} \mathrm{PCR} \mathrm{buffer}$ (10x) \{Roche\}, and $0.25 \mu \mathrm{l} \mathrm{Tag}$ DNA polymerase $(5 \mathrm{unit} / \mu \mathrm{l})\{$ Roche $\}$. The reaction mixture was thermo-cycled. The PCR products were stored at $4^{\circ} \mathrm{C}$. Positive and negative controls were included in all the tests. Each microlitre aliquot of every PCR product was mixed with $2 \mu \mathrm{l}$ of loading buffer (6x). The PCR products and a $100 \mathrm{bp}$ DNA ladder were then separated by electrophoresis on $1 \%$ agarose gel and stained with $0.5 \mu \mathrm{l} / \mathrm{ml}$ ethidium bromide $(100 \mathrm{~V}$ for $1 \mathrm{~h}$ ) following a UV transluminator.

\section{Purification and sequencing}

For gene sequence analysis, PCR fragments of 19 isolates were purified using a High Pure PCR Product Purification Kit (Roche Diagnostics) and then sent to MWG Company for sequencing to confirm the PCR results.

\section{Processing of sequence data}

The nucleotide sequences of the 13 isolates ( 6 isolates failed) were in agreement with MWG Company. Sequence analysis and multiple computer alignment of these sequences were done according to the Clustal W algorithm by using the Bio Edit software package. After manually aligning the refinement, the evolutions were constructed by the neighbor-joining algorithm included in the phylogeny program package MEGA version 5.04; a phylogenetic relationship was established and a tree was derived by neighborjoining (Saitou and Nei, 1987). Phylogenetic relationships were compared with species-specific sequencing of $M$. agalactiae 


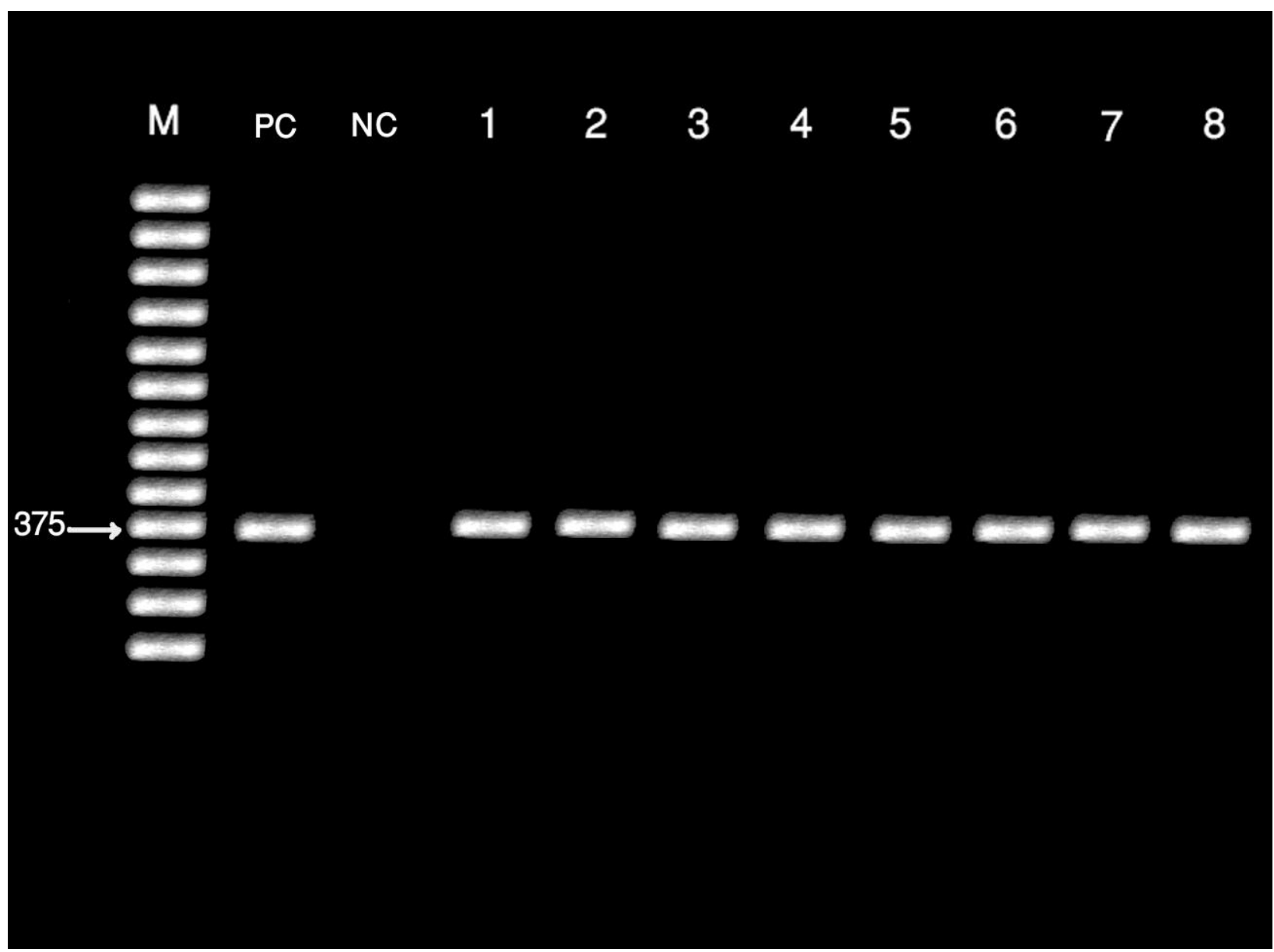

Figure 1. Specificity of the PCR detection assay using the primers FS1 and FS2. M: marker 100 bp; PC: positive control [M. agalactiae (NCTC 10123)]; NC: negative control [PPLO broth media]; 1 to 8: positive Mycoplasma genus samples. The formation of $375 \mathrm{bp}$ in 8 positive species

deposited in GenBank. A sequence identity matrix was represented (Clustal W) and a phylogenetic tree was built by neighbor-joining.

\section{RESULTS}

For the PCR test, 19 isolates from a previous study, which originated from Kerman province, were positive for M. agalactiae and showed a specific amplicon at $375 \mathrm{bp}$ (Figure 1). Therefore, P80 gene of 13 different isolates of $M$. agalactiae field strains were sequenced by MWG Company and 6 isolates failed. Sequence analysis reveal significant variability among these isolates. The nucleotide sequences data from 13 isolates show homology differences and indicates the presence of different $M$. agalactiae strains in Kerman province isolates (Figure 2). The isolates in this study were classified into two different groups according to their phylogenetic relatedness. There were no differences in the nucleotide sequences of the P80 gene among members of these two different groups. Phylogenetic distances among the strains are shown in Figure 3.
Among the isolates, seven showed identical nucleotide sequence, meaning they represent the same strains. Isolates MAgR32, MAgR18, MAgR3, MAgR34, MAgR25, MAgR33 and MAgR23 formed a distinct cluster and most homology values were achieved between MAgR18 with MAgR3 and MAgR23 (99.4\%), while the least homology was achieved between MAgR33 with MAgR3, MAgR23 and MAgR34 (84.1\%). In addition, other isolates, namely MAgR31, MAgR29, MAgR30, MAgR24, MAgR22 and MAgR35, all represent the same strain; in this cluster, the highest homology was achieved between MAgR31 with MAgR29 and MAgR24 (98.9\%) and the least homology was achieved between MAgR22 and MAgR24 (80.6\%). Another Iranian strain (accession no. HQ722028.1), which was isolated in Kordestan Province, Iran, from sheep (Moradi Bidhendi et al., 2011) was obtained from GenBank. This strain has high homology with members of the second cluster, the highest homology with MAgR35 $(97.8 \%)$ and the least homology with MAgR3, MAgR23 and MAgR34 (48.0\%). Vaccinal strain (accession no. FJ15950.1) used at Razi Vaccine and Serum Research Institute, Karaj, Iran, for vaccine production, forms a dis- 

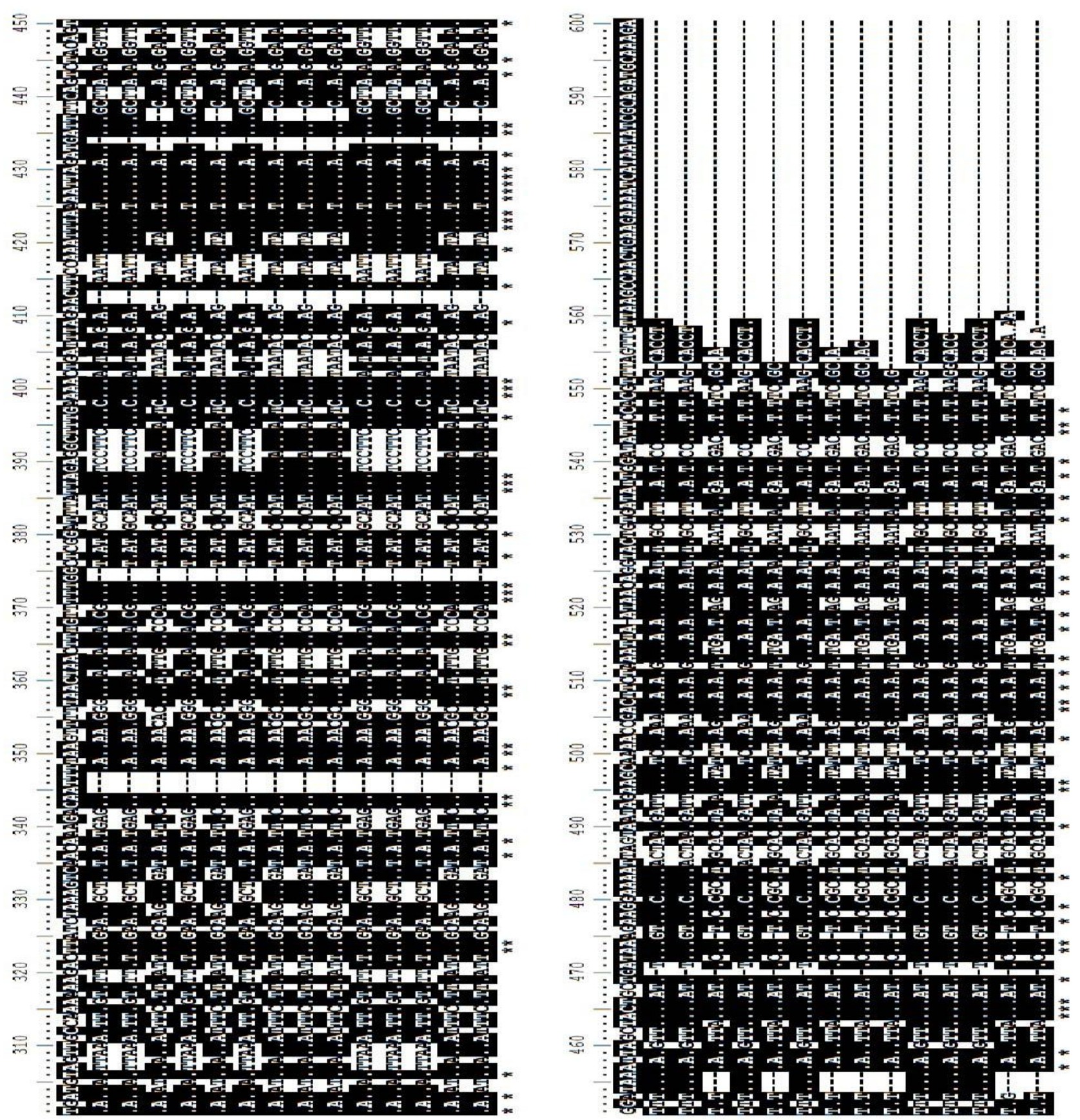

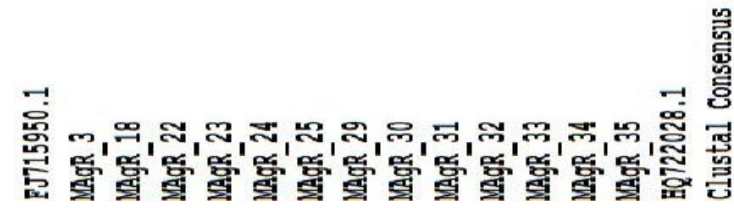

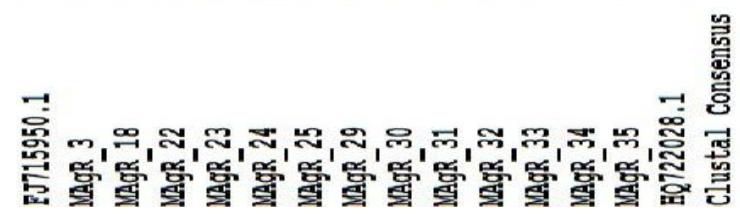

Figure 2. illustration of a sequence alignment of mycoplasma P80 gene within Iranian isolates and vaccine strain.

tinct cluster that is different from all other Iranian isolates originating from Kerman and Kordestan province. This strain has poor homology with all of them (identities 21.0 to $25.9 \%$ ) (Figure 3).

\section{DISCUSSION}

In Iran, $M$. agalactiae is majorly responsible for contagious agalactia outbreaks in goats. Sheep flocks 


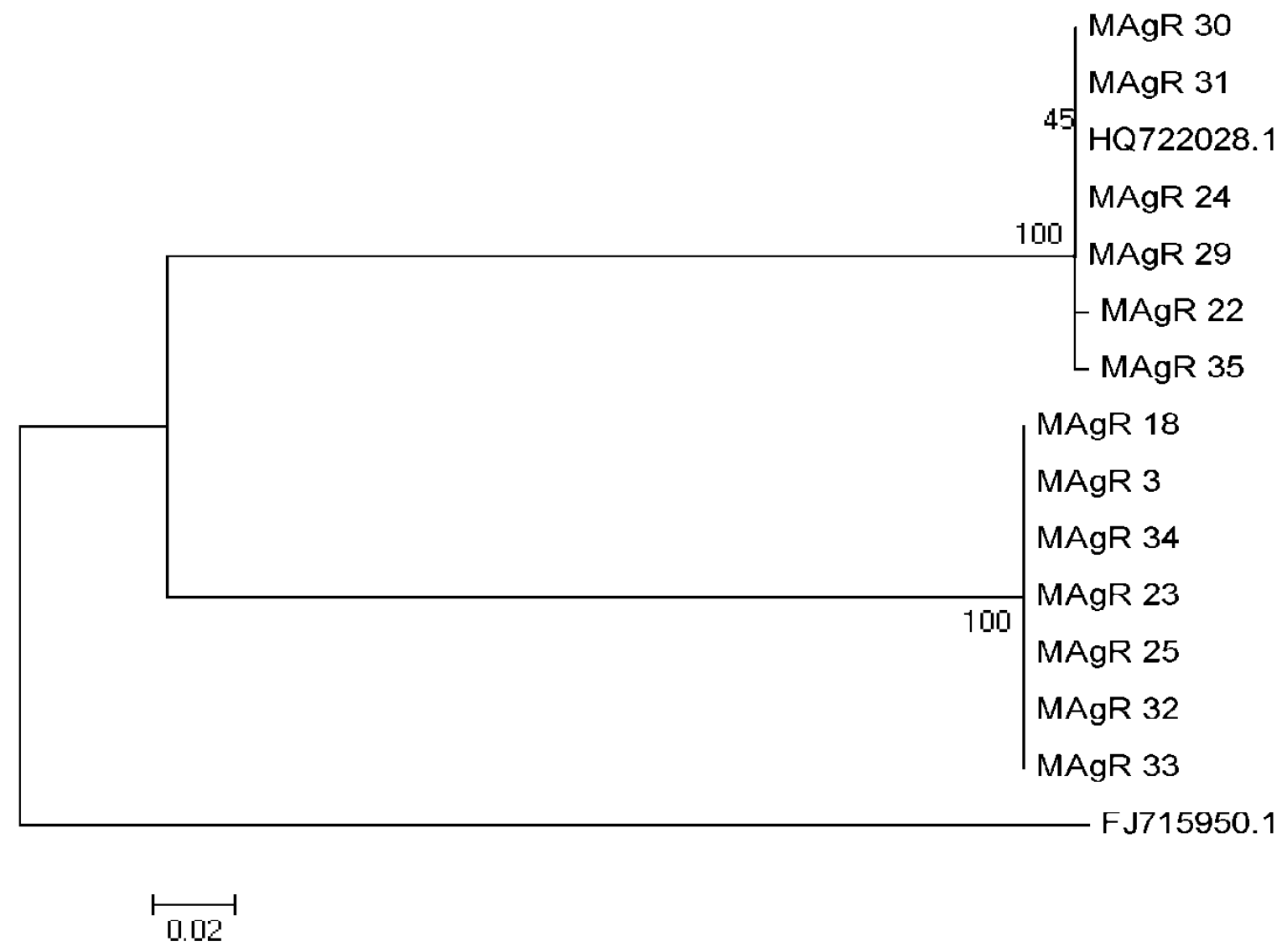

Figure 3. Representation of the phylogenetic relationship of all Iranian $M$. agalactiae isolates analyzed. A distance matrix was calculated by the Clustal W algorithm by using a Bio Edit software package, and this phylogenetic tree was built by the neighbor-joining method. Bootstrap values of 1000 simulations are given at the branching points of the tree. FJ715950.1 is the vaccinal strain, and HQ722028.1 is the Iranian sheep isolate.

are also affected and previous studies show that contagious agalactia is present in Iranian sheep (Moradi Bidhandi et al., 2011). The systematic computer alignment of mycoplasmal P80 gene sequences and phylogenetic analysis allowed the identification and comparison of variable regions of the gene sequence of $M$. agalactiae isolated from Kerman Province goat herds. A phylogenetic study of Iranian goats' isolated $M$. agalactiae is described in this paper for the first time in Iran. The results presented here indicate that interspecies sequence differences in the mycoplasmal P80 gene made Iranian isolated strains of $M$. agalactiae to be classified into two different groups. In this study, the P80 gene sequences provide the basis for a phylogenetic analysis of the mycoplasmas because mycoplasmal pathogenecity is most closely related to this gene. The results reported in the present paper confirm nucleotide sequence identity of Iranian isolates of $M$. agalactiae as a major agent of contagious agalactia in goats. In this report, much attention focuses on the comparison between Iranian isolates of goats and one isolate from Iranian sheep and a vaccinal strain. Past studies have shown that pathogenic mycoplasmas are equipped with a sophisticated genetic system, which allows these agents to spontaneously change their surface antigenic make-up (Jechlinger et al., 2004). Mahdavi et al. (2009) in a comparative study of nucleotide sequence of P40 gene in vaccinal strains (Shiraz, Taleghan and Lorestan strains), reported that the highest homology was achieved between a Shiraz strain and a Lorestan strain (99.7\%), while the least homology was achieved between a Shiraz strain and a Taleghan strain (74.6\%). This vaccinal strain used in Iranian goat herds for immunogenicity against contagious agalactia as well as in our study, and nucleotide sequences of the P80 gene in $M$. agalactiae isolates from affected goats in these herds were compared with a vaccine. The results given in a recent comparative study confirm poor homology between the vaccinal strain and the detected $M$. agalactiae in goat herds. This study allowed us to perform a molecular epidemiological study of $M$. agalactiae in Kerman province and we suggested that the distribution of other mycoplasma agents including Mycoplasma mycoides subsp. Mycoides LC, Mycoplasma capricolum subsp. capricolum and Mycoplasma putrefaciens should be compared in different areas of Iran. 
In conclusion, we have utilized a molecular method for identifying $M$. agalactiae based on the P80 gene. This report demonstrates that the vaccine strain has poor homology with a detected pathogenic strain of $M$. agalactiae in goat herds, and we recommend that the detected species should be included in future contagious agalactia vaccine production in order to improve the efficiency of the agalactia vaccine, although it require more specific researches.

\section{ACKNOWLEDGEMENTS}

This research was supported by the Reference Mycoplasma Laboratory, Razi Vaccine and Serum Research Institute, Karaj, Iran and the Faculty of Specialized Veterinary Sciences, Islamic Azad University, Science and Research Branch, Tehran, Iran.

\section{REFERENCES}

De La Fe C, Amores J, Corrales JC, Martin AG, Sanches A, Contreras A (2009). Comparison of culture and PCR to detect Mycoplasma agalactiae and Mycoplasma mycoides subsp Capri in ear swabs taken from goats. Vet. Microbiol. 140:105-110.

European Pharmacopoeia (2005). Test for mycoplasmas, 1:2.6.7.

Hasani tabatabayi A. Firouzi R (2005). Disease of animals due to bacteria. Tehran Uni. Pre. pp. 469-480.

Jechlinger W, Chopra-Dewasthaly R, Glew M, Citti C, Rosengarten R (2004). Mulecular basis of Mycoplasma agalactiae pathogenicity. Beri Munch Tierarzti Wochenschr, 117(11-12):472-479.

Kheirkhah B, Pourbakhsh SA, Nadalian MG, Banani M, Ashtari A (2011). Detection of Mycoplasma agalactiae by culture and polymerase chain reaction (PCR) methods from Iranian goats. Afr. J. Microbiol. Res. 5(13):1668-1672.
Kojima A, Takahashi T, Kijima M, Ogikubo Y, Nishimura Y, Nishimura S, Arasawa R, Tamura $Y$ (1997). Detection of mycoplasma in avian live virus vaccines by polymerase chain reaction. Biologicals 25:365371.

Mahdavi S, Zahraei Salehi T, Madani R, Keyvanfar H (2009). Comparative study of homology of cytoplasmic membrane protein 40 $\mathrm{KDa}$ of Mycoplasma agalactiae in isolated strains in Iran. Afr. J. Microbiol. Res. 9:528-532.

Moradi Bidhendi S, Khaki P, Pilehchian Langroudi R (2011). Isolation and identification of Mycoplasma agalactiae by culture and polymerase chain reaction in sheep and goat milk samples in Kordestan Province, Iran. Arch. Razi Ins. 66(1):11-16.

Oravcová K, López-Enríquez L, Rodríguez-Lázaro D, Hernández M (2008). Mycoplasma agalactiae p40 gene, a novel diagnostic marker for contagious agalactia in sheep by real-time PCR: assessment of the analytical performance and in-house validation in natural contaminated milk samples. J. Clin. Microbiol. Accepts, published online.

Saitou N, Nei M (1987). The neighbor-joining method: a new method for reconstructing phylogenetic trees. Mol. Biol. Evol. 4:406-425.

Tola S, Angioi A, Rocchigiani AM, Idini G, Manunta D, Galleri G, Leori G (1997). Detection of Mycoplasma agalactiae in sheep milk samples by polymerase chain reaction. Vet. Microbiol. 54(1):17-22.

Van Kuppeveld FJM, van der Logt JTM, Angulo AF, van Zoest MJ, Quint WGV, Niesters HGM, Galama JMD, Melchers WJG (1992). Genus and species-specific identification of mycoplasmas by $16 \mathrm{~S}$ rRNA amplification. App. Enviro. Microbiol. 58(8):2606-2615.

Waters AP, McCutchan TF (1990). Ribosomal RNA: nature's own polymerase-amplified target for diagnosis. Parasitol. Today 6:56-59.

Zendulkova D, Madanat A, Lany P (2007). Detection of Mycoplasma agalactiae by polymerase chain reaction in Jordanian Sheep and goat herds, Acta. Vet. Brono. 76:71-77. 